\title{
Kematangan gonad dan tipe pemijahan ikan lais, Ompok miostoma (Vaillant, 1902) di Daerah Aliran Sungai Mahakam Kalimantan Timur
}

[Gonad maturity and spawning type of silurid catfishes, Ompok miostoma (Vaillant, 1902) from Mahakam watershed, East Kalimantan]

\author{
Jusmaldi $^{1 \bowtie}$, Dedy Duryadi Solihin ${ }^{2}$, Ridwan Affandi ${ }^{3}$, MF Rahardjo $^{3}$, Rudhy Gustiano ${ }^{4}$ \\ ${ }^{1}$ Program Studi Biologi FMIPA Universitas Mulawarman Samarinda, \\ Jln. Barong Tongkok no 4 Kampus Gunung Kelua, Samarinda 7512 \\ ${ }^{2}$ Departemen Biologi, Fakultas Matematika dan Ilmu Pengetahuan Alam \\ ${ }^{3}$ Departemen Manajemen Sumber Daya Perairan, Fakultas Perikanan dan Ilmu Kelautan \\ Institut Pertanian Bogor, Kampus IPB Dramaga, Bogor 16680 \\ ${ }^{4}$ Balai Penelitian dan Pengembangan Budidaya Air Tawar, \\ Jl. Sempur No.1, Bogor 16154
}

Diterima: 2 Mei 2017; Disetujui: 23 Mei 2017

\begin{abstract}
Abstrak
Ikan lais O. miostoma (Vaillant 1902) adalah spesies ikan endemik di Daerah Aliran Sungai (DAS) Mahakam Kalimantan Timur. Aspek biologi reproduksi ikan ini belum pernah diketahui. Penelitian ini bertujuan untuk menentukan karakteristik tahap kematangan gonad, ukuran telur, dan tipe pemijahan. Pengambilan contoh ikan dilakukan setiap bulan, dari bulan November 2013 sampai Oktober 2014 menggunakan berbagai jenis alat tangkap pada empat lokasi penelitian di DAS Mahakam yang meliputi: Danau Semayang, Sungai Belayan, Sungai Siran, dan Sungai Tering. Penentuan tingkat kematangan gonad ikan lais dilakukan dengan metode pemeriksaan morfologis dan histologis. Tipe pemijahan ikan lais ditentukan berdasarkan sebaran diameter telur. Hasil penelitian menunjukkan ada lima tahap kematangan gonad jantan dan betina ikan lais. Sebaran diameter telur pada tahap matang gonad berkisar dari $0,54-1,30 \mathrm{~mm}$ dengan tipe pemijahan serempak.
\end{abstract}

Kata penting: tingkat kematangan gonad, sebaran diameter telur, tipe pemijahan, ikan lais, Sungai Mahakam

\begin{abstract}
Silurid catfishes O. miostoma (Vaillant, 1902) is an endemic species in Mahakam Watershed East Kalimantan. Biology reproduction aspect of this species is not yet known. The purpose of this study was to determine the stages of gonad maturation characteristics, egg size, and spawning type. Fish sampling conducted monthly from November 2013 to October 2014, using many gears at four locations in Mahakam Watershed, i.e: Semayang Lake, Belayan River, Siran River and Tering River. To determine the stages of gonad maturation in silurid catfishes were carried out by morphologic and histologic examination methods. Spawning fish type was determined based on the distribution of eggs diameter. The results of this research showed that there are five gonad maturation stages of males and females of silurid catfishes. Distribution of eggs diameter in gonad maturity stages ranges from $0.54-1.30 \mathrm{~mm}$ with simultaneous spawning type.
\end{abstract}

Key words: gonad maturation stages, distribution of eggs diameter, spawning type, Silurid catfishes, Mahakam River

\section{Pendahuluan}

Ikan lais Ompok miostoma (Vaillant, 1902) termasuk di dalam anggota famili Siluridae merupakan spesies ikan air tawar bersungut (catfishes), endemik Sungai Mahakam Kalimantan Timur (Kottelat 2013). Ikan ini sebelumnya diidentifikasi sebagai O. bimaculatus (Bloch, 1794) (Christensen 1992, Kottelat 1994). Habitat ikan ini ditemukan di sepanjang aliran Sungai

$\triangle$ Penulis korespondensi Alamat surel: aldi_jus@yahoo.co.id
Mahakam terutama di kawasan hulu dan tengah termasuk danau, rawa, dan anak sungainya.

Informasi biologi reproduksi spesies ikan dalam genus Ompok baru diketahui pada beberapa spesies tertentu seperti $O$. hypophthalmus di Sungai Kampar Riau (Sjafei et al. 2008, Elvyra 2009), O. pabda di Sungai Gomoti dan Muhuri Tripura India (Banik et al. 2012, Gupta et al. 2014), dan O. malabaricus di Sungai Amaravathy Tamil Nadu India (Arthi et al. 2013). 
Pada berbagai jenis catfishes, perkembangan gonad berdasarkan pengamatan morfologis dan histologis dilaporkan berbeda pada masing masing spesies. Pada Auchenoglanis occidentalis proses kematangan gonad terbagi atas enam tahap (Shinkafi \& Ipinjolu 2012) dan Eutropiichthys vacha terbagi atas lima tahap (Soomro et al. 2012).

Tipe pemijahan juga berbeda antar spesies ikan, hal tersebut berkaitan erat dengan perkembangan sel telur di dalam ovariumnya. Berdasarkan dinamika pengorganisasian sel telur dalam ovarium, Murua \& Saborido-Rey (2003) mengemukakan ada tiga tipe pemijahan ikan, yakni (I) Sinkroni, yaitu seluruh sel telur berkembang dan diovulasikan pada waktu yang sama. Ovari seperti ini dapat ditemukan pada ikan teleostei yang pemijahannya hanya sekali dan kemudian mati; (2) Sinkroni berkelompok, yaitu ikan yang memiliki dua populasi sel telur. Sel telur yang besar dikeluarkan pada musim pemijahan pertama dan selanjutnya sel telur yang kecil akan dikeluarkan pada musim pemijahan berikutnya; (3) Asinkroni, yaitu kelompok ikan yang tidak memiliki populasi sel telur yang dominan pada seluruh tahap perkembangan.

Pemeriksaan karakteristik setiap tahap perkembangan gonad sangat penting untuk mengetahui siklus reproduksi ikan, waktu dan frekuensi pemijahan, ukuran telur, serta penentuan ukuran panjang ikan kali pertama matang gonad (Goncalves et al. 2006, Arianti et al. 2017). Oleh karena itu pemeriksaan tahap perkembangan gonad ikan secara morfologis dan histologis sangat perlu dilakukan.

Penelitian tentang aspek biologi reproduksi spesies O. miostoma (Vaillant, 1902) di perairan
Sungai Mahakam khususnya tahap kematangan gonad dan tipe pemijahan belum pernah dilaporkan. Berdasarkan hal tersebut tujuan penelitian ini adalah mendeskripsikan dan menentukan karakteristik tahap kematangan gonad ikan lais secara morfologis dan histologis serta tipe pemijahannya.

\section{Bahan dan metode}

\section{Waktu dan tempat penelitian}

Penelitian ini dilaksanakan dari bulan November 2013 - Oktober 2014. Lokasi pengumpulan sampel ikan lais dilakukan di perairan $\mathrm{Su}-$ ngai Mahakam seperti pada Gambar 1. Analisis morfologis dan histologis gonad serta pengukuran diameter telur dilakukan di Laboratorium Histologi Universitas Mulawarman Samarinda.

\section{Koleksi sampel}

Penangkapan ikan dilakukan setiap bulan di masing-masing lokasi dengan menggunakan beberapa alat tangkap seperti: jaring insang eksperimental dan alat perangkap bamboo (bubu) dan pancing. Jaring insang eksperimental berukuran mata jaring $1 ; 1,5 ; 2 ; 2,5$ dan 3 inci dengan panjang $20 \mathrm{~m}$ dan tinggi $2 \mathrm{~m}$. Jaring insang dipasang selama tiga hari dan diperiksa setiap 2 jam sekali. Bubu sebanyak 10 buah dipasang selama dua hari dua malam.

Jumlah ikan yang dikoleksi sebanyak yang didapatkan pada setiap bulan. Ikan yang tertangkap segera diawetkan di dalam larutan formalin $10 \%$, disimpan dalam kain kasa dan dimasukkan dalam kantung plastik kemudian ditulis lokasi, tanggal dan bulan pengambilan, dan segera dibawa ke Laboratorium. 


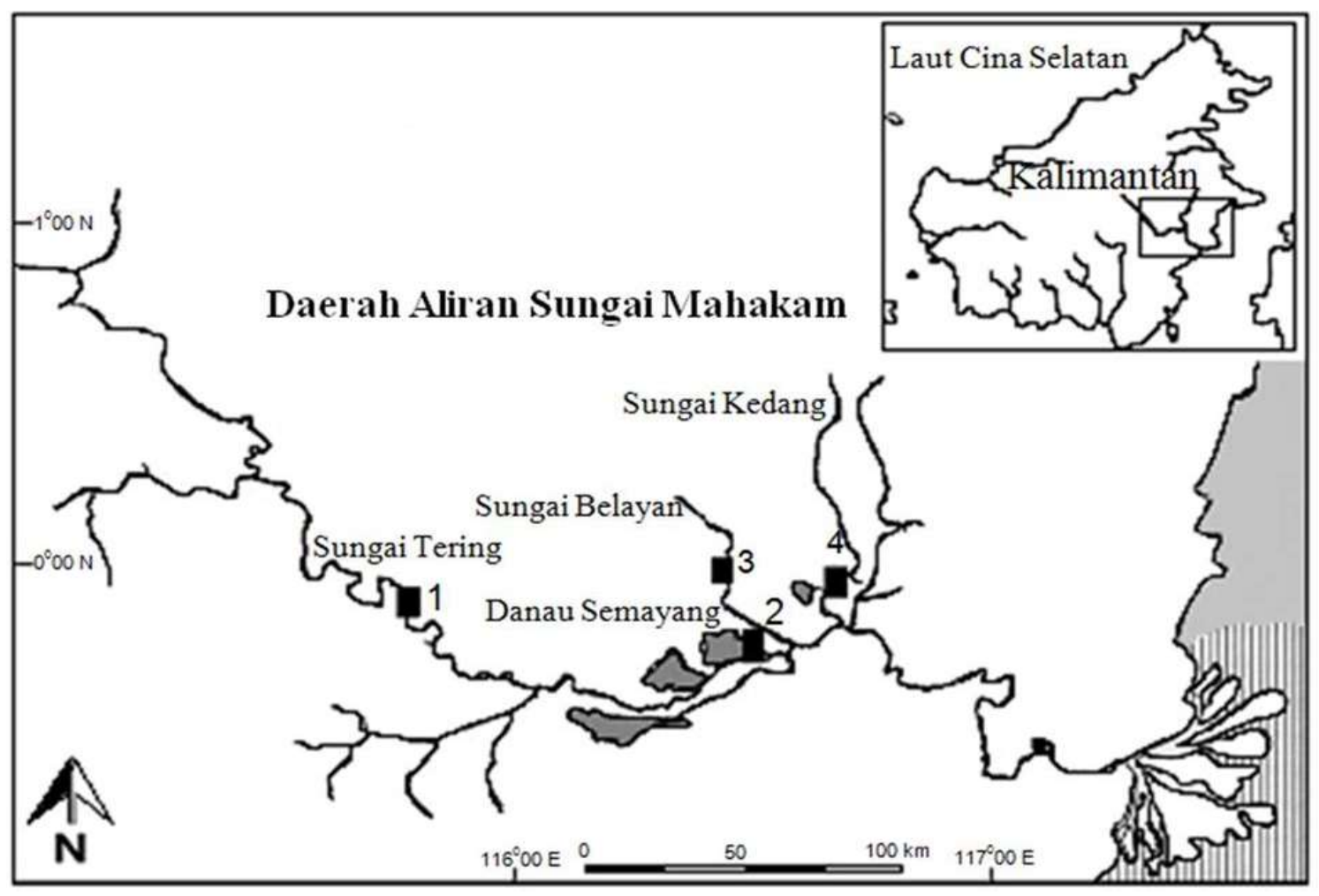

Gambar 1. Lokasi koleksi sampel ikan di perairan Sungai Mahakam. Koordinat lokasi: 1= Sungai Tering $\left(00^{0} 04^{\prime} 03^{\prime \prime} \mathrm{LS} ; 115^{0} 40^{\prime} 05^{\prime \prime} \mathrm{BT}\right), 2$ = Danau Semayang $\left(00^{0} 11^{\prime} 09.8^{\prime \prime} \mathrm{LS} ; 116^{0} 27^{\prime} 31.2^{\prime \prime} \mathrm{BT}\right)$, 3 = Sungai Belayan $\left(00^{0} 12^{\prime} 18.2^{\prime \prime}\right.$ LS ; $116^{0} 31^{\prime} 55.3^{\prime \prime}$ BT $), 4$ = Sungai Kedang Muara Siran $\left(00^{0} 07^{\prime} 26.1^{\prime \prime} \mathrm{LS} ; \mathrm{E} 116^{0} 37^{\prime} 56.4^{\prime \prime} \mathrm{BT}\right)$

Penentuan jenis kelamin dan tahap kematangan gonad

Pembedahan ikan lais dilakukan mulai dari anus sampai tutup insang menggunakan alat bedah, dengan tujuan untuk mendapatkan gonad ikan. Penentuan tahap kematangan gonad pada ikan lais dilakukan dengan dua cara yaitu secara morfologis dan histologis.

Penentuan tahap kematangan gonad secara morfologis ditentukan berdasarkan bentuk, warna, ukuran, bobot gonad serta perkembangan isi gonad (Effendie 2002). Setelah dilakukan pengamatan morfologis, selanjutnya gonad ikan jantan dan betina pada masing-masing tahap diawetkan dengan menggunakan larutan Bouin's. Gonad ikan lais jantan dan betina diambil secara acak untuk membuat preparat awet histologis dengan menggunakan metode mikroteknik.
Pembuatan preparat awet histologis gonad dilakukan menurut prosedur yang dilakukan oleh Gunarso (1989) sebagai berikut:

Tahap fiksasi jaringan gonad. Contoh gonad dipotong 5 -10 mm kemudian dilakukan fiksasi dengan menggunakan $200 \mathrm{ml}$ larutan Bouin's (sediaan larutan Bouin's terdiri atas campuran asam pikrat jenuh $1500 \mathrm{ml}$, formalin $500 \mathrm{ml}$, asam asetat glasial $100 \mathrm{ml}$ ) selama 24 jam, kemudian dipindahkan ke dalam alkohol 70\% selama 24 jam.

Tahap dehidrasi. Gonad direndam dalam alkohol 70\% (24 jam), alkohol 80\% (2 jam), alkohol 90\% (2 jam), alkohol 95\% (1 jam), alkohol 100\% (12 jam), dan alkohol 100\% (1 jam).

Tahap penjernihan kesatu. Gonad direndam dalam alkohol 100\% ditambah xylol (1:1) selama 30 menit kemudian direndam dalam xylol I, xylol II, dan xylol III masing-masing selama 30 menit. 
Tahap penyusupan. Gonad direndam dalam xylol ditambah paraffin (1:1) selama 45 menit pada oven bersuhu $65-70^{\circ} \mathrm{C}$. Selanjutnya direndam dalam paraffin I, paraffin II, dan paraffin III masing-masing selama 45 menit yang dipanaskan dalam oven yang bersuhu $65-70^{\circ} \mathrm{C}$, kemudian jaringan dicetak dalam cetakan selama 12 jam (proses blocking).

Tahap pemotongan. Pemotongan dengan $m i$ crotom, spesimen dipotong tipis dengan ketebalan 4 sampai 6 mikron, kemudian hasil potongan diletakkan di atas gelas objek dengan bantuan diapungkan di atas air hangat $\left(50^{\circ} \mathrm{C}\right)$.

Tahap deparaffinasi dan rehidrasi. Preparat direndam berturut-turut dalam xylol I, xylol II, xylol III masing-masing selama 5 menit dan selanjutnya dilakukan rehidrasi, preparat direndam berturut-turut dengan alkohol 100\% I, alkohol 100\% II, alkohol 95\% I, alkohol 95\% II, alkohol $85 \%$, alkohol $80 \%$, alkohol $70 \%$, dan alkohol $50 \%$ masing-masing selama 2 menit kemudian preparat dicuci dengan aquades sampai warna putih.

Tahap pewarnaan. Preparat direndam berturut-turut dalam larutan hematoksilin selama 5-7 menit, kemudian dicuci dengan air kran mengalir selama 5-7 menit kemudian preparat direndam dalam larutan eosin selama 3 menit dan dicuci dengan air kran mengalir.

Tahap dehidrasi. Preparat direndam berturutturut dalam alkohol 50\%, alkohol 70\%, alkohol $80 \%$, alkohol $85 \%$, alkohol $90 \%$, alkohol $100 \%$ pertama, dan alkohol 100\% kedua, masing-masing selama 2 menit.

Tahap penjernihan kedua dan penempelan. Preparat direndam dalam xylol I, xylol II, dan xylol III masing-masing selama 2 menit, kemudian dilakukan penempelan dan preparat diberi zat perekat canada balsam, dan ditutup dengan kaca penutup dan dibiarkan selama 12 jam.
Penentuan tingkat kematangan gonad ikan lais secara histologis dilakukan dengan pengamatan preparat histologis gonad melalui mikroskop. Tingkat kematangan gonad secara histologis dianalisis merujuk pada Atlas of Fish Histology (Genten et al. 2009).

Tingkat kematangan gonad ikan jantan dan betina yang telah diklasifikasikan secara morfologis dan histologis, hasilnya difoto dan kemudian dianalisis dan dideskripsikan sehingga diperoleh karakteristik perkembangan gonad pada masing-masing tahap.

\section{Diameter telur dan tipe pemijahan}

Data diameter telur diperoleh dari hasil pengukuran dengan mikrometer okuler. Data diameter telur selanjutnya ditentukan jumlah kelas dan selang kelasnya. Frekuensi relatif diameter telur pada setiap selang kelas dihitung dengan menggunakan rumus:

Frekuensi relatif diameter telur $=\frac{\mathrm{mi}}{\mathrm{M}} \times 100$

Keterangan: $\mathrm{m}_{\mathrm{i}}=$ jumlah telur pada selang ke I, $\mathrm{M}=$ jumlah total butir telur yang diperiksa.

Frekuensi relatif diameter telur pada masing masing selang kelas dianalisis dalam bentuk grafik histogram. Tipe pemijahan ditentukan berdasarkan frekuensi relatif sebaran diameter telur pada tiap selang kelas. Apabila terlihat dua atau lebih modus penyebaran, tipe pemijahannya bertahap. Jika satu modus penyebaran, tipe pemijahan serempak.

\section{Hasil}

Tahap kematangan gonad (TKG)

Pada tahap awal perkembangan gonad, ikan lais jantan memiliki ukuran 162,62 $\pm 5,54 \mathrm{~mm}$, sedangkan betina memiliki ukuran 160,56 \pm 7,61 $\mathrm{mm}$. Secara umum, gonad jantan dan betina terletak dorso lateral dari usus dan menempel pada dinding tubuh dorsal oleh mesorchium di dalam 
rongga abdomen (rongga perut). Pada tahap belum berkembang, morfologi gonad jantan (testis) terbagi dua, berbentuk lembaran tipis, berukuran pendek, melengkung dan bewarna putih bening, sedangkan gonad betina (ovari) terbagi dua, berwarna putih kemerahan, berukuran pendek dan permukaan licin.

Berdasarkan hasil pembedahan dan pengamatan terhadap tahap kematangan gonad (TKG) pada ikan jantan dan betina, maka perkembangan gonad ikan lais ditetapkan lima tahap yaitu TKG
I (tidak matang), TKG II (awal pematangan), TKG III (pematangan), TKG IV (matang) dan TKG V (salin). Posisi gonad di dalam rongga abdomen ikan lais jantan dan betina pada lima tahapan tingkat kematangan gonad tersebut dapat dilihat pada Gambar 2. Deskripsi karakteristik masing-masing tingkat kematangan gonad secara morfologis dan histologis pada ikan lais jantan diperlihatkan pada Gambar 3 dan Tabel 1, sedangkan pada ikan lais betina diperlihatkan pada Gambar 4 dan Tabel 2.

Tabel 1. Karakteristik tingkat kematangan gonad (TKG) ikan lais O. miostoma (Vaillant, 1902) jantan secara morfologis dan histologis

\begin{tabular}{|c|c|c|}
\hline TKG & Morfologis & Histologis \\
\hline I & $\begin{array}{l}\text { Testis terbagi dua, berbentuk lembaran dengan } \\
\text { pinggiran berigi pendek, ukuran relatif kecil, } \\
\text { panjang mencapai } 1 / 8 \text { rongga perut. Testis ber- } \\
\text { warna putih susu kemerahan, terletak di bagian } \\
\text { posterior rongga perut di bawah ginjal. }\end{array}$ & $\begin{array}{l}\text { Spermatogonium melekat di dinding tubulus } \\
\text { seminiferus dan sebagian spermatogonium } \\
\text { telah berkembang menjadi spermatozit primer. }\end{array}$ \\
\hline II & $\begin{array}{l}\text { Ukuran testis lebih besar dan bentuk gerigi } \\
\text { lebih jelas dari TKG I. Panjang mencapai } 1 / 5 \\
\text { rongga perut. Testis berwarna putih susu ke- } \\
\text { merahan. }\end{array}$ & $\begin{array}{l}\text { Testis lebih berkembang dibandingkan TKG I } \\
\text { dan jaringan ikat terlihat makin sedikit. Kan- } \\
\text { tong-kantong tubulus seminiferus berisi sper- } \\
\text { matozit primer. Selisih ukuran spermatogonium } \\
\text { dan spermatozit primer sangat kecil. }\end{array}$ \\
\hline III & $\begin{array}{l}\text { Gerigi pada pinggiran testis lebih besar daripa- } \\
\text { da TKG II, warna testis makin putih, ukuran } \\
\text { testis makin besar, panjang mencapai } 1 / 4 \text { pan- } \\
\text { jang rongga perut. }\end{array}$ & $\begin{array}{l}\text { Spermatosit primer berkurang karena sebagian } \\
\text { besar telah berkembang menjadi spermatozit } \\
\text { sekunder. Spermatid telah terlihat dan letaknya } \\
\text { menyebar di dalam tubulus seminiferus. }\end{array}$ \\
\hline IV & $\begin{array}{l}\text { Ukuran testis makin membesar, panjang men- } \\
\text { capai } 1 / 3 \text { rongga perut, gerigi pada pinggiran } \\
\text { testis lebar dan tebal. Testis semakin pejal. } \\
\text { Warna seperti putih susu. }\end{array}$ & $\begin{array}{l}\text { Spermatid telah memenuhi tubulus seminiferus. } \\
\text { Terjadi proses spermiogenesis (spermatid ber- } \\
\text { ubah menjadi spermatozoa). Pada akhir spermi- } \\
\text { ogenesis spermatozoa di lepaskan pada lumen } \\
\text { tubulus seminiferus. }\end{array}$ \\
\hline V & $\begin{array}{l}\text { Gerigi pada pinggiran testis pada bagian terten- } \\
\text { tu terlihat kosong dan mengempis. Warna putih } \\
\text { bening. Panjang mencapai } 1 / 5 \text { hingga } 1 / 4 \\
\text { rongga perut. }\end{array}$ & $\begin{array}{l}\text { Terlihat sisa-sisa spermatozoa yang belum di- } \\
\text { keluarkan pada saat pemijahan. Bagian tertentu } \\
\text { dari tubulus seminiferus terlihat kosong karena } \\
\text { sperma telah dikeluarkan. }\end{array}$ \\
\hline
\end{tabular}



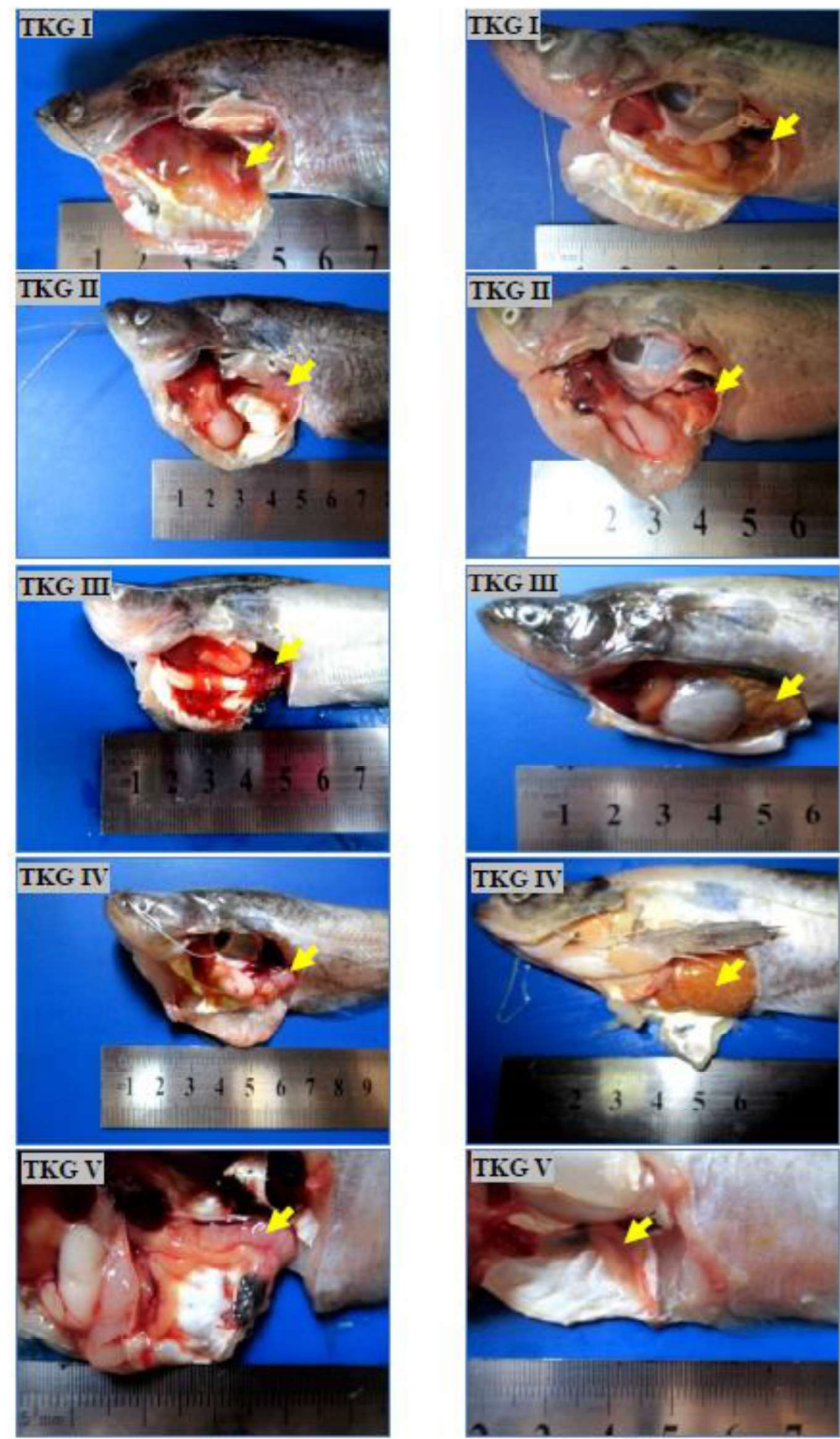

(a)

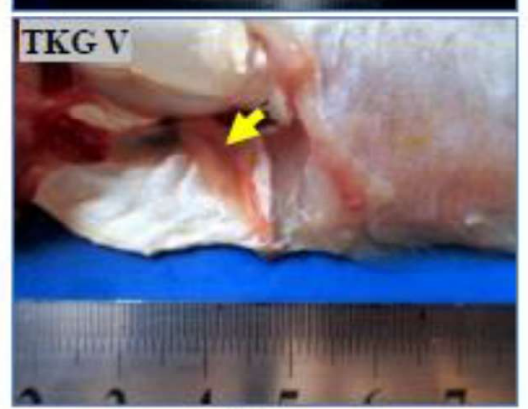

(b)

Gambar 2. Posisi gonad ikan jantan (a) dan betina (b) dalam rongga perut $O$. miostoma (Vaillant 1902). Keterangan: tanda panah menunjukkan posisi gonad dalam rongga abdomen. 

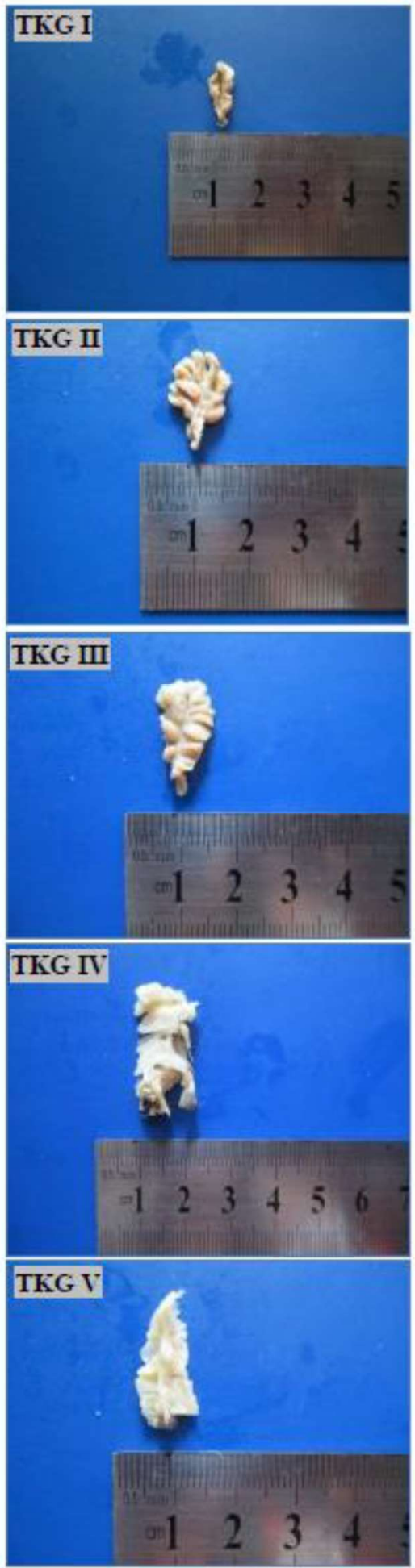

(a)
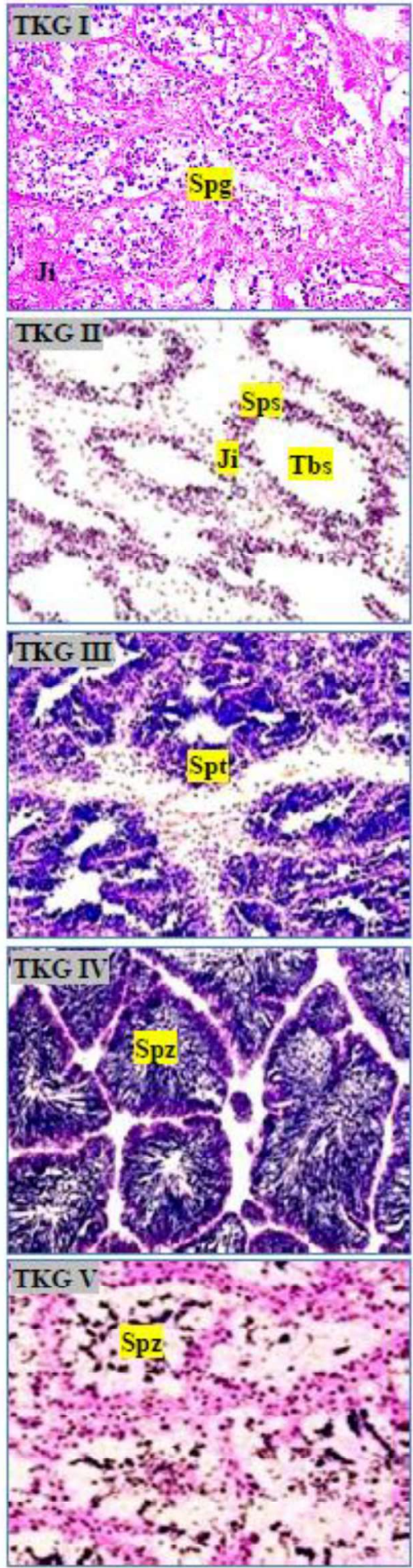

(b)

Gambar 3. Struktur morfologis (a) dan histologis (b) gonad jantan O. miostoma (Vaillant, 1902). Keterangan: Spg: spermatogonium; Ji: jaringan ikat gonad; Sps: spermatosit; Tbs: tubulus seminiferus; Spt: spermatid; Spz: spermatozoa. Pewarnaan dengan hematoksilin dan eosin (perbesaran $10 \times 10)$. 

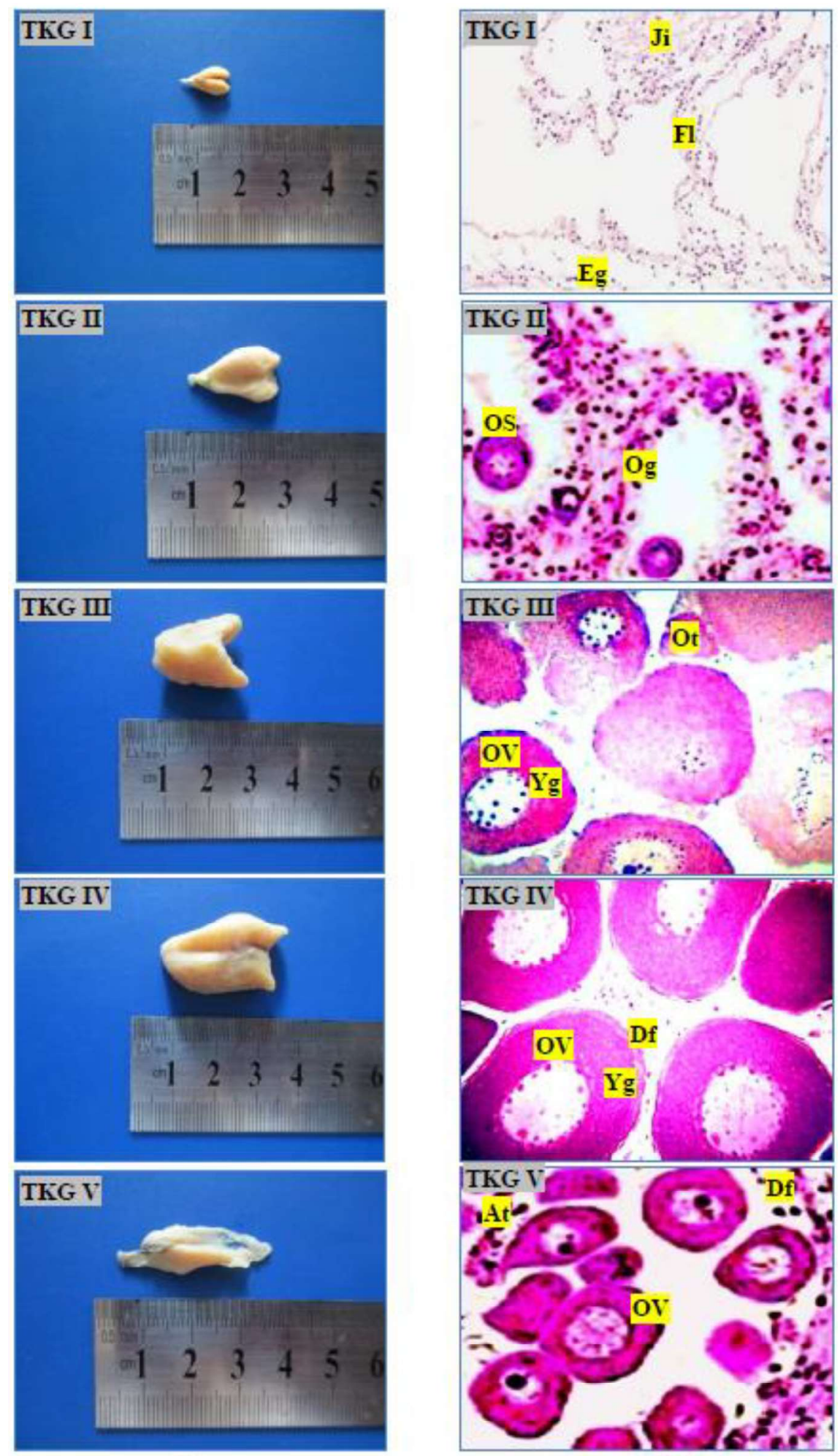

(a)

(b)

Gambar 4. Struktur morfologis (a) dan histologis (b) gonad betina O. miostoma (Vaillant, 1902). Keterangan: Ji: jaringan ikat; Fl: sel folikel; Eg: epitel geminal; Og: oogonium; Os: oosit; Ot: ootid; Yg: granula kuning telur; Ov: ovum; Df: dinding folikel; At: atresia. Pewarnaan dengan hematoksilin dan eosin (perbesaran 5 x10). 
Tabel 2. Karakteristik tingkat kematangan gonad (TKG) ikan lais O. miostoma (Vaillant, 1902) betina secara morfologis dan histologis

\begin{tabular}{|c|c|c|}
\hline TKG & Morfologis & Histologis \\
\hline I & $\begin{array}{l}\text { Ovarium sepasang, berbentuk oval, ukuran re- } \\
\text { latif kecil, terletak di bagian posterior rongga } \\
\text { perut. Butir telur dalam ovarium tidak terlihat } \\
\text { dengan mata, bewarna putih kemerahan dan } \\
\text { permukaan ovarium licin. }\end{array}$ & $\begin{array}{l}\text { Dinding lamela tersusun oleh epitel germinal } \\
\text { yang disokong oleh jaringan ikat dan sel-sel fo- } \\
\text { likel mulai terlihat. Sel-sel folikel terlihat ber- } \\
\text { warna ungu pada permukaan epitel germinal. }\end{array}$ \\
\hline II & $\begin{array}{l}\text { Bagian anterior ovarium terdapat lekukan dan } \\
\text { ukuran ovarium relatif lebih besar daripada } \\
\text { TKG I. Ovarium bewarna merah gelap, butir } \\
\text { telur dalam ovarium belum terlihat jelas de- } \\
\text { ngan mata. Ovarium mengisi kira-kira } 1 / 6 \text { dari } \\
\text { rongga perut. }\end{array}$ & $\begin{array}{l}\text { Sebagian sel folikel berubah menjadi oogonium } \\
\text { dan oosit primer. Kantung kuning telur sudah } \\
\text { mulai terbentuk di lapisan perifer sitolasma (de- } \\
\text { kat membran sel). Proses ini disebut sebagai } \\
\text { tahap awal vitellogenesis. }\end{array}$ \\
\hline III & $\begin{array}{l}\text { Telur mulai kelihatan butirnya dengan mata, } \\
\text { tetapi belum dapat dipisahkan. Ovarium ber- } \\
\text { warna kecoklatan, mengisi } 1 / 3 \text { rongga perut. }\end{array}$ & $\begin{array}{l}\text { Jumlah oosit primer semakin bertambah dan le- } \\
\text { taknya mendekati lumen ovarium. Sebagian } \\
\text { oosit sekunder telah berkembang menjadi ootid. } \\
\text { Butir kuning telur dan vacoala minyak menye- } \\
\text { bar mulai dari inti mengarah ketepi. }\end{array}$ \\
\hline IV & $\begin{array}{l}\text { Ovarium makin besar, telur bewarna kuning } \\
\text { dan mudah dipisahkan. Bagian anterior ova- } \\
\text { rium terbelah kira kira } 1 / 3 \text { panjang dari ova- } \\
\text { rium. Ovarium mengisi } 1 / 2-2 / 3 \text { rongga perut, } \\
\text { usus tampak terdesak. }\end{array}$ & $\begin{array}{l}\text { Ovarium didominasi oleh ootid dan ovum. Vite- } \\
\text { llogenesis telah selesai. Inti bermigrasi ke tepi } \\
\text { dan mendekati mikropil dan melebur ke dinding } \\
\text { sel. }\end{array}$ \\
\hline V & $\begin{array}{l}\text { Dinding ovarium tebal, pada bagian posterior- } \\
\text { nya mengempis dan terdapat butir telur sisa di } \\
\text { dekat saluran pelepasan. Warna ovarium sama } \\
\text { seperti TKG IV. Ovarium mengisi kira - kira } \\
\text { 1/4 rongga perut. }\end{array}$ & $\begin{array}{l}\text { Dinding folikel terlihat telah pecah dan sel telur } \\
\text { telah di keluarkan. Terdapat sisa sel telur yang } \\
\text { tidak dikeluarkan. Sel-sel telur yang tidak dike- } \\
\text { luarkan terlihat mengalami atresia dan beberapa } \\
\text { oogonium sudah mulai terlihat. }\end{array}$ \\
\hline
\end{tabular}

Tabel 3. Sebaran diameter telur ikan lais berdasarkan tingkat kematangan gonad

\begin{tabular}{cccc}
\hline \multirow{2}{*}{ Kelompok Diameter Telur (mm) } & \multicolumn{3}{c}{ Frekuensi (\%) } \\
\cline { 2 - 4 } & TKG III & TKG IV & TKG V \\
\hline $0,54-0,60$ & 0,78 & 0 & 0 \\
$0,61-0,67$ & 1,22 & 0,91 & 13,00 \\
$0,68-0,74$ & 3,56 & 3,08 & 15,67 \\
$0,75-0,81$ & 10,11 & 7,26 & 18,00 \\
$0,82-0,88$ & 19,22 & 10,71 & 22,00 \\
$0,89-0,95$ & 38,33 & 14,13 & 24,67 \\
$0,96-1,02$ & 14,22 & 40,85 & 6,67 \\
$1,03-1,09$ & 6,78 & 8,58 & 0 \\
$1,10-1,16$ & 5,78 & 7,38 & 0 \\
$1,17-1,23$ & 0 & 5,01 & 0 \\
$1,24-1,30$ & 0 & 2,08 & 0 \\
\hline
\end{tabular}



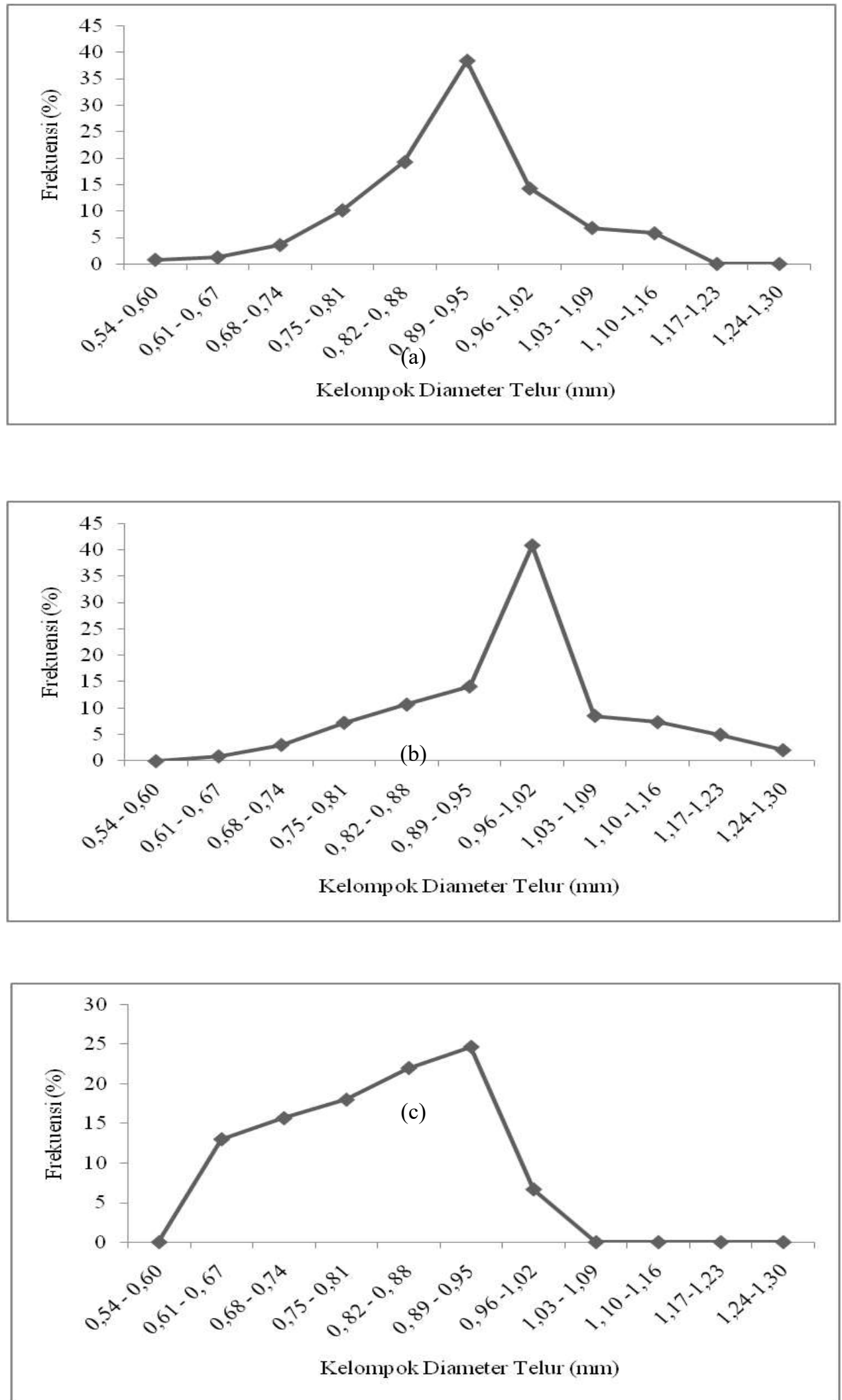

Gambar 5. Sebaran diameter telur ikan lais pada TKG III (a), TKG IV (b), dan TKG V (c) 
Sebaran diameter telur dan tipe pemijahan

Sebaran diameter telur ikan lais dari TKG III hingga TKG IV berkisar dari 0,54-1,30 mm yang terbagi atas 11 kelompok ukuran seperti terlihat pada Tabel 3.

Pada TKG III diameter telur berkisar dari 0,54-1,16 $\mathrm{mm}$ dan frekuensi tertinggi pada kelompok ukuran 0,89-0,95 mm. Pada TKG IV diameter telur berkisar dari 0,61-1,30 $\mathrm{mm}$ dan frekuensi tertinggi ditemukan pada kelompok ukuran 0,96-1,02 mm. Pada TKG V diameter telur berkisar dari 0,65-0,98 mm dengan frekuensi tertinggi ditemukan pada kelompok ukuran 0,89$0,95 \mathrm{~mm}$.

Pergeseran puncak kurva ke arah kanan dari TKG III ke TKG IV menunjukkan bahwa semakin tinggi tingkat kematangan gonad maka diameter telur akan semakin besar. Namun pada TKG V ketika ikan telah memijah kurva kembali bergeser ke kiri. Kurva ke arah kiri pada TKG V menunjukkan sisa telur yang tidak dikeluarkan pada saat ikan lais memijah. Berdasarkan pergeseran kurva dari TKG III hingga TKG V diperkirakan diameter telur yang dikeluarkan pada saat ikan memijah berada pada kelompok ukuran 0,96-1,30 mm seperti terlihat pada Gambar 5 .

\section{Pembahasan}

Dalam penelitian ini tahap perkembangan ikan lais yang diperiksa secara morfologis dan histologis diklasifikasikan menjadi lima tahap pada jenis kelamin jantan dan betina, yaitu TKG I (tidak matang), TKG II (awal pematangan), TKG III (pematangan), TKG IV (matang) dan TKG V (salin). Jika dibandingkan dengan spesies lainnya dalam genus Ompok, tahap perkembangan gonad yang sama ditemukan pada spesies $O$. hypophthalmus (Sjafei et al. 2008, Elvyra 2009).

Pemeriksaan morfologis gonad ikan jantan pada masing-masing tahap menunjukkan terda- patnya perbedaan rigi pada bagian pinggir testis, warna, ukuran dan bobot, sedangkan secara histologis ditunjukkan oleh perbedaan perkembangan sperma dan persebaran sperma yang mengisi bagian tubulus seminiferus dari testis. Pada gonad ikan betina pemeriksaan secara morfologis gonad pada masing-masing tahap perkembangan menunjukkan adanya perbedaan dalam penampakan butir telur, warna ovarium, dan ukuran ovarium yang dibandingkan dengan ukuran rongga perut, sedangkan pemeriksaan histologis menunjukkan perbedaan bentuk, ukuran sel telur dan migrasi inti sel telur. Ferreri et al. (2009) menyatakan penetapan tahap kematangan gonad secara histologis dapat mengungkapkan lebih rinci proses perkembangan sel telur dan sperma sehingga memungkinkan identifikasi setiap tahap menjadi lebih tepat.

Secara keseluruhan sebaran diameter telur ikan lais dari TKG III hingga TKG V berkisar dari 0,54-1,30 mm. Pergeseran puncak kurva ke arah kanan dari TKG III ke TKG IV menunjukkan bahwa semakin tinggi tingkat kematangan gonad maka diameter telur akan semakin besar. Berdasarkan pergeseran kurva dari TKG III hingga TKG V diperkirakan diameter telur yang dikeluarkan pada saat ikan memijah berada pada kelompok ukuran 0,96-1,30 mm. Pada O. pabda diameter telur pada saat telur matang gonad berkisar antara 0,548-0,806 mm (Banik et al. 2012), sedangkan pada $O$. hypophthalmus frekuensi tertinggi diameter telur pada saat matang gonad berkisar antara 0,94-1,03 mm (Sjafei et al. 2008).

Sebaran diameter telur ikan lais hanya memiliki satu modus yang bergerak ke kanan. Berdasarkan pola sebaran diameter telur, maka seluruh telur akan dikeluarkan ketika ikan memijah. Tipe pemijahan yang demikian dinamakan pemijahan serempak. Pola serupa juga ditemukan pa- 
da kelompok catfish lainnya seperti pada ikan Chrysichthys aurotus (Ikomi \& Odum 1998).

\section{Simpulan}

Hasil penelitian yang telah dilakukan terhadap perkembangan tahap kematangan gonad dan sebaran diameter telur $O$. miostoma (Vaillant, 1902) di Sungai Mahakam dapat ditarik kesimpulan sebagai berikut: tahap kematangan gonad O. miostoma (Vaillant, 1902) jantan dan betina secara morfologis dan histologis dibagi atas lima tahap dan masing-masing tahap ditemukan karakteristik yang berbeda. Sebaran diameter telur berkisar dari 0,54 - 1,30 $\mathrm{mm}$ dan memiliki satu modus yang mengindikasikan pola pemijahan $O$. miostoma (Vaillant, 1902) adalah serempak.

\section{Daftar pustaka}

Arianti ND, Rahardjo MF, Zahid A. 2017. Perkembangan sel telur ikan seriding, Ambassis nalua (Hamilton 1822). Jurnal Iktiologi Indonesia, 17(1): 115-123

Arthi T, Nagarajan S, Sivakumar AA, Vijayaraman K. 2013. Reproductive biology of two freshwater fishes, Ompok bimaculatus and O. malabaricus (Bloch) of the River Amaravathy, Tamil Nadu, India. Biolife, 1(2): 4553.

Banik S, Goswami P, Acharjee T, Malla S. 2012. Ompok pabda (Hamilton-Buchanan, 1822): an endangered catfish of Tripura, India: reproductive physiology related to freshwater lotic environment. Journal of Environment, 1 (2): 45-55.

Christensen MS. 1992. Investigations on the ecology and fish fauna of the Mahakam River in East Kalimantan (Borneo), Indonesia. Internationale Revue der gesamten Hydrobiologie, 77(4): 593-608.

Effendie MI. 2002. Biologi perikanan. Yayasan Pustaka Nusatama,Yogyakarta.163 hlm.

Elvyra R. 2009. Kajian keragaman genetik dan biologi reproduksi ikan lais di sungai Kampar Riau. Disertasi. Institut Pertanian Bogor. Bogor. $126 \mathrm{hlm}$.
Ferreri R, Basilone G, d'Elia M, Traina A, Saborido-Rey F, Mazzola S. 2009. Validation of macrocopic maturity stages according to microscopic histological examination for European anchovy. Marine Ecology, 30(1): 181-187.

Genten F, Terwinghe E, Danguy A. 2009. Atlas of Fish Histology. Science Publishers, United States of America (US). 215 p.

Goncalves TL, Bazzoli N, Brito MFG. 2006. Gametogenesis and reproduction of the matrinxa, Brycon orthotaenia (Gunther, 1864) (Pisces, Characidae) in the Sao Francisco River, Minas Gerais, Brazil. Brazilian Journal of Biology, 66(2A): 513-522.

Gupta BK, Sarkar UK, Bhardwaj SK. 2014. Reproductive biology of Indian silurid catfish Ompok pabda in river Gomti. Journal of Enviromental Biology, 35(2): 345-351.

Gunarso W. 1989. Bahan pengajaran mikroteknik. Departemen Pendidikan dan Kebudayaan, Direktorat Jendral Pendidikan Tinggi, Pusat Antar Universitas Ilmu Hayat, Institut Pertanian Bogor, Bogor.

Ikomi RB, Odum O. 1998. Studies on aspects of the ecology of the catfish Chrysichthys auratus Geoffrey St, Hilaire (Osteichthyes: Bagridae) in the River Banin (Niger Delta, Nigeria). Fisheries Research, 35(3): 209-218.

Kottelat M. 1994. The fishes of the Mahakam River, east Borneo: an example of the limitations of zoogeographic analyses and the need for extensive surveys in Indonesia. Tropical Biodiversity, 2(3): 401- 426.

Kottelat M. 2013. The fishes of the inland waters of Southeast Asia: a catalogue and core bibliography of the fishes known to occur in freshwaters, mangroves and estuaries. Raffles Bulletin of Zoology, 27: 1 - 663.

Murua H, Saborido-Rey F. 2003. Female reproductive strategies of marine fish species of the North Atlantic. Journal of Northwest Atlantic Fishery Science, 33: 23-31.

Shinkafi BA and Ipinjolu JK. 2012. Gonadosomatic index, fecundity and egg size of Auchenoglanis occidentalis (Cuvier \& Valenciennes) in River Rima, North-Western Nigeria. Nigerian Journal of Basic and Applied Science 20(3): 217-224

Sjafei DJ, Simanjuntak CPH, Rahardjo MF. 2008. Perkembangan kematangan gonad dan tipe pemijahan ikan selais (Ompok 
hypophthalmus) di rawa banjiran Sungai Kampar Kiri, Riau. Jurnal Iktiologi Indonesia 8(2): 93-100.

Soomro AN, Baloch WA, Jafri SIH, Burdi GH, Fulanda B. 2012. Reproduction and feeding habits of the river catfish Eutropiichthys vacha (Hamilton, 1822) (Siluriformes, Schilbidae) in an impacted habitat: Kotri hydrodam, River Indus, Pakistan. Our Nature, 10(1): 269-280. 